\title{
Um Estudo das Manifestações Patológicas e das Condições Estruturais da Ponte sobre o Rio Iga- rassu na BR 101/PE
}

Title: A study of pathological manifestations and structural conditions of the bridge over the river in Iguassu BR 101/PE

Dayse Câmara Pereira dos Santos

Escola Politécnica de Pernambuco

Universidade de Pernambuco

50.720-001 - Recife, Brasil

daysecamaraps@gmail.com

\author{
José Afonso Pereira Vitório \\ Escola Politécnica de Pernambuco \\ Universidade de Pernambuco \\ 50.720-001 - Recife, Brasil \\ afonsovitorio@gmail.com
}

\begin{abstract}
Resumo A ponte sobre o Rio Igarassu, construída no início da década de 1960, tem uma grande importância para o tráfego da BR-101 Norte no Estado de Pernambuco devido ao grande fluxo de veículos que se destinam ao polo industrial de Goiana e aos Estados da Paraíba e Rio Grande do Norte. Essa obra de Arte Especial, passa atualmente por estado bastante avançado de degradação estrutural, especialmente nas vigas do tabuleiro de concreto armado. Por se tratar de uma obra implantada em área de alta agressividade ambiental, e não ter recebido manutenções regulares ao longo de todas essas décadas, apresenta uma situação aparentemente de risco para os usuários que trafegam sobre ela. Nesse sentido, este trabalho se propõe em fazer uma análise dos fenômenos patológicos que atuam na ponte, a partir de vistorias, visando propor alternativas para a correção de tais problemas, de modo a possibilitar o restabelecimento das condições apropriadas de estabilidade e funcionalidade.
\end{abstract}

Palavras-Chave: Pontes, estruturas, patologias, recuperação e reforço

\begin{abstract}
The bridge over the River Igarassu, built in the early 1960s, has a great importance for traffic of BR-101 North in Pernambuco due to the large flow of vehicles intended for the industrial center of Goiana and the States Paraiba and Rio Grande do Norte. This work of Special Art, is currently undergoing a fairly advanced state of structural deterioration, especially in the beams of reinforced concrete board. Because it is a work set in a high environmental aggressiveness area and have not received regular maintenance throughout all these decades, it presents a seemingly risky situation for users who travel on it. In this sense, this paper aims to make an analysis of the concepts and pathological phenomena that act on the bridge, from surveys, aiming to propose alternatives for the correction of such problems in order to enable the re-establishment of appropriate conditions of stability and functionality.
\end{abstract}

Keywords: Bridges, structures, disease, recovery and strengthening 


\section{Introdução}

A falta de manutenção preventiva nas pontes de Pernambuco implica na necessidade de estudos sobre as reais condições dessas obras para evitar grandes problemas ao tráfego e riscos aos usuários. A ponte objeto deste estudo está localizada sobre o rio Igarassu na BR 101 Norte e foi construída no início da década de 1960 com estrutura em concreto armado, sem receber uma adequada manutenção ao longo de todo esse tempo. Atualmente ela encontra-se em péssimo estado de conservação, com avançada degradação estrutural no tabuleiro, principalmente nas longarinas extremas. Fatores ambientais como atmosfera marinha, proximidade de indústrias e baixo cobrimento das armaduras, contribuíram para a situação atual. Nas vistorias foram observadas patologias diversas, destacando-se a corrosão das armaduras, eflorescências e desplacamento do concreto.

\section{Metodologia}

A metodologia adotada para este estudo consistiu em inspeção realizada de forma visual com registro fotográfico, identificando as possíveis patologias. As informações coletadas incluíram a localização, idade, comprimento, largura, os materiais da superestrutura/ mesoestrutura e a tipologia da estrutura.

\section{Revisão bibliográfica relacionada ao objeto deste estudo}

\subsection{Durabilidade}

"É a capacidade que um produto, componente ou construção possui de manter o seu desempenho acima dos níveis mínimos especificados, de maneira a atender às exigências dos usuários, em cada situação especificada"'[1].

\subsection{Vida Útil}

É o tempo em que a estrutura se mantém dentro de um limite mínimo de comportamento em serviço para o qual foi projetada, sem elevar os custos de manutenção e reparação [2].

Segundo a NBR 6118/2014, as estruturas de concreto armado devem ser projetadas e construídas de modo que, sob condições ambientais previstas na época do projeto, e mantendo a sua utilização conforme preconizado em projeto, conservem sua segurança, estabilidade, e aptidão em serviço, durante o prazo correspondente à sua vida útil

\subsection{Patologia e Terapia das Construções}

Patologia em engenharia pode ser definida como sendo o estudo dos sintomas, dos mecanismos, das causas e das origens dos defeitos das construções civis, ou seja, é o estudo das partes que compõem o diagnóstico do problema [1].

As patologias podem ter origem nas fases de projeto e de execução e dependem da agressividade do meio e/ou de fenômenos atípicos.

Terapia estuda a escolha e a administração do tratamento para solução dos problemas patológicos. Para que se tenha sucesso no tratamento faz-se necessário um diagnóstico bem feito. A terapia a ser aplicada, nada mais é do que a consequência do processo investigativo.

O diagnóstico adequado é aquele que contemplam todos os aspectos do problema, que são: sintomas, mecanismos, origem e causas.

\subsection{Principais Patologias nas Estruturas de Concreto}

\subsubsection{Corrosão das armaduras}

Corrosão é uma interação destrutiva de um material com o ambiente, seja por reação química, ou eletroquímica [3].

Também é definida como a deterioração dos materiais pela ação química ou eletroquímica do meio, podendo estar ou não associada a esforços mecânicos [4].

\subsubsection{Classificação dos processos de corrosão.}

Dependendo do tipo de ação do meio corrosivo sobre o material, os processos corrosivos podem ser classificados em químico ou eletroquímico. De acordo com GENTIL (1994) [4]. No primeiro processo ocorrem reações químicas diretas entre o material metálico, ou nãometálico, com o meio corrosivo, podendo ou não haver transferências de cargas ou de elétrons e, portanto, não havendo a formação de uma corrente elétrica. No segundo processo ocorrem transferências de cargas ou elétrons através de uma interface entre metal e eletrólito. É um processo no qual há um ânodo e um cátodo, e a água presente no concreto serve de eletrólito. Assim, qualquer diferença de potencial entre os pontos pode gerar uma corrente.

A corrosão eletroquímica é o fenômeno mais típico de estruturas de concreto expostas à atmosfera marinha, como é o caso da estrutura em estudo. Trata-se de um processo no qual há um ânodo e um cátodo, e a água presente no concreto serve de eletrólito. Assim, qualquer diferença de potencial entre os pontos pode gerar uma corrente, iniciando a corrosão [5]. 


\subsubsection{Manifestação da Corrosão}

A corrosão pode se manifestar das seguintes formas nas armaduras das estruturas de concreto [2]:

- Manchas superficiais no concreto.

- Expansão das barras de armaduras.

- Fissuração do concreto.

- Destacamento da camada de cobrimento de concreto.

- Redução da seção das armaduras.

- Perda de aderência das armaduras.

\subsubsection{Mecanismos da Corrosão}

Todo problema patológico ocorre através de um mecanismo. No caso da corrosão das armaduras os principais mecanismos são a carbonatação e a contaminação por cloretos.

A carbonatação é a transformação dos hidróxidos de cálcio com $\mathrm{pH}$ alto em carbonato cálcio que tem um $\mathrm{pH}$ neutro. A existência de umidade no concreto, a quantidade de $\mathrm{CO}_{2}$ do meio ambiente, a permeabilidade do concreto e a existência de fissuras influenciam bastante o avanço desse fenômeno, que é um dos mecanismos mais responsáveis pala deterioração do concreto armado.

A taxa de carbonatação depende de vários fatores, particularmente da permeabilidade do concreto (quanto mais permeável maior será a taxa) e da umidade relati$\mathrm{va}[6]$.

A ponte em estudo aparenta ter um concreto bastante permeável, proporcionando a ação da carbonatação. A utilização do indicador fenolftaleína, permite determinar in loco a profundidade da frente de carbonatação nas superfícies expostas das estruturas de concreto

O caso da contaminação por íons cloretos pode se dar pela própria composição do concreto, pela presença na água ou em aditivos aceleradores de pega que contenham cloreto de cálcio $\mathrm{CaCl}_{2}$.

Os cloretos são encontrados no concreto em diferentes formas: combinados quimicamente ao C-S-H ou como cloroaluminatos adsorvidos fisicamente ás paredes dos poros, ou livres na solução dos poros do concreto[5].

Podem ser também provenientes do ambiente, quando em contato com a água do mar, atmosfera marinha, poluentes industriais ou em contato com produtos químicos. A norma da ABNT-NBR 6118/2014-Estipula algumas diretrizes quanto ao risco de deterioração das estruturas de concreto em função da agressividade do ambiente em que serão inseridas. A ponte em estudo se enquadra no tipo III - Agressividade forte: risco de deterioração grande, atmosfera marinha e ambientes industriais.

\subsubsection{Lixiviação}

É um processo patológico que ocorre nas estruturas de concreto, devido à infiltração de água, que dissolve e transporta cristais de hidróxidos de cálcio e magnésio, podendo formar depósitos de sais conhecido como eflorescência. Com a perda de sólidos, a estrutura fica com sua resistência mecânica reduzida e também abre caminho para entrada de gases e líquidos nocivos à armadura $\mathrm{e}$ ao próprio concreto, causando dentre outros problemas a corrosão das armaduras e a carbonatação do concreto [7].

\subsubsection{Eflorescência}

A eflorescência ocorre devido à solubilidade do hidróxido de cálcio $\mathrm{Ca}(\mathrm{OH})_{2}$ na presença de umidade. Essa patologia ocasiona manchas devido à precipitação do carbonato de cálcio $\mathrm{CaCO}_{3}$ na superfície do concreto e da evaporação da água que contém o hidróxido dissolvido. $\mathrm{O}$ processo acontece em concreto com alta permeabilidade ou fissurados e são encontrados com frequência em lajes e vigas[8].

\subsubsection{Fissuras}

São fenômenos próprios e inevitáveis do concreto arma-do. São aberturas que afetam a superfície da estrutura, transformando-se em um caminho rápido para a entrada de agentes agressivos[8]. As fissuras podem ser classificadas como ativas ou passivas. Na ponte objeto deste estudo as fissuras são provavelmente passivas pois aparentam estar estabilizadas.

\subsubsection{Desagregação}

É a deterioração causada pela separação das partes do concreto, provocada pela expansão devido à oxidação ou dilatação das armaduras. Podendo também ser pelo aumento do volume do concreto devido a absorção de água[9].

\section{Descrição da ponte estudada}

A ponte sobre o Rio Igarassu construída na década de 1960 encontra-se em uma área de alta agressividade ambiental, fato que, contribuiu para o aparecimento de significativas manifestações patológicas ao longo de décadas de uso.

Com uma extensão de $27,10 \mathrm{~m}$ e largura de $8,34 \mathrm{~m}$, a ponte tem tabuleiro em grelha de concreto armado com 4 longarinas com inércia variável e dois vãos iguais, apoiadas nas extremidades em encontros de concreto e em pilar-parede no meio do vão conforme mostram as figuras $1 \mathrm{e} 2$. No tabuleiro existem cinco transversinas, sendo três intermediárias e duas extremas. É possível identificar que em um dos encontros os aparelhos de apoio são do tipo pêndulo. No outro encontro e no apoio central não foi possível identificar os aparelhos de apoio, 
porém é possível presumir que se tratem de chapas de chumbo, que eram muito utilizadas na época.

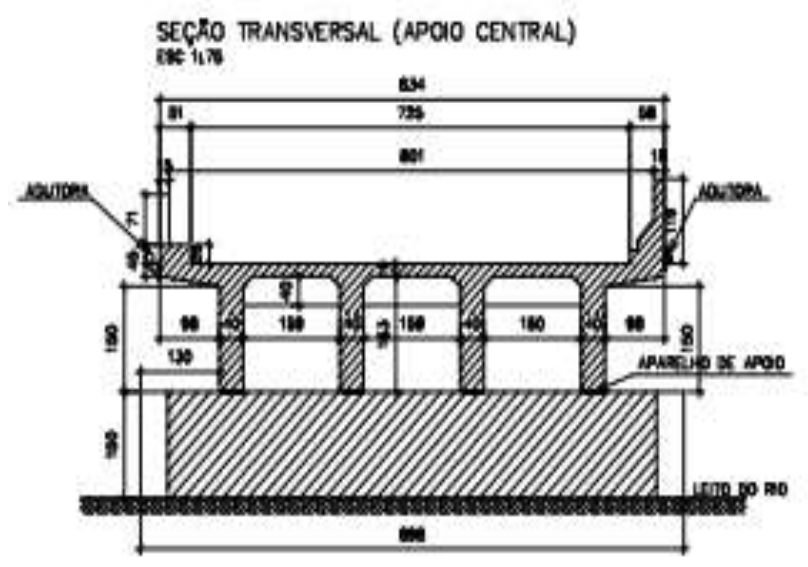

Figura 1: seção transversal no apoio central pilar-parede

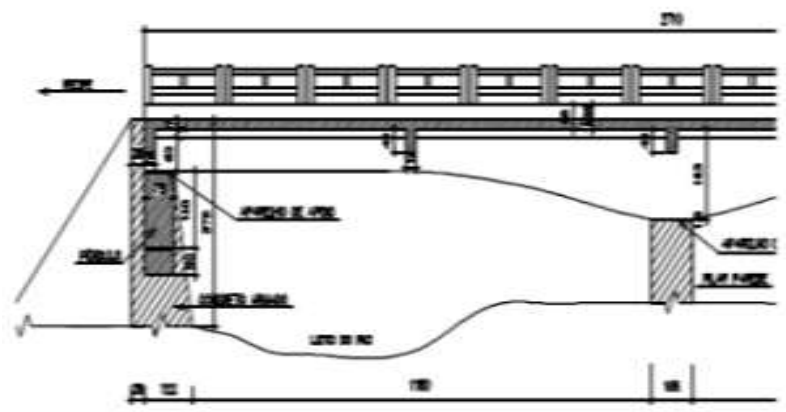

Figura 2: 1/2 corte longitudinal na ponte

Foi observada a ausência dos passeios de pedestres e apenas um guarda-corpo no lado direito sentido Goiana. No outro lado existe barreira de proteção em concreto do tipo New Jersey conforme mostra a Figura 3.

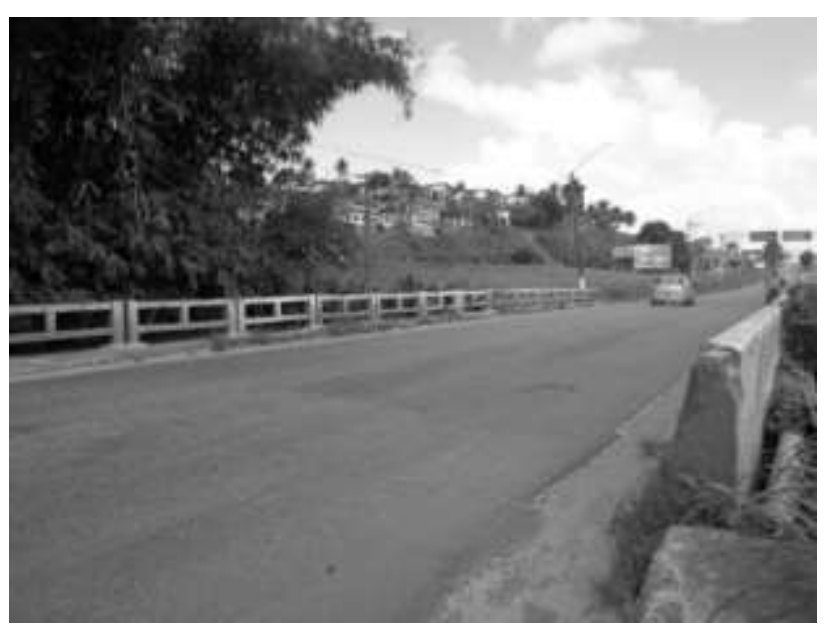

Figura 3: Vista superior da ponte
A pista de rolamento sobre o tabuleiro é de CBUQ, observando-se ainda a ausência de drenos para escoar a água sobre a ponte.

\subsection{Geometria}

Trata-se de uma obra cujo a estrutura é descrita a seguir:

Superestrutura: tabuleiro em grelha com vigas de inércia variável.

Mesoestrutura: encontros / pilar-parede

Largura do tabuleiro: $7,25 \mathrm{~m}$

Comprimento do tabuleiro: $27,10 \mathrm{~m}$

O tabuleiro é composto por 02 vãos de $13,55 \mathrm{~m}$

\subsection{Principais danos e manifestações pa- tológicas existentes.}

$\mathrm{Na}$ vistoria realizada, foram observadas as diversas manifestações patológicas e danos estruturais, decorrentes da própria idade da obra, da sua localização em uma área de alta agressividade ambiental e principalmente da falta de manutenções preventivas e corretivas. A seguir são descritas as principais avarias identificadas na ponte analisada, considerando as super, meso e infraestrutura.

\subsubsection{Na superestrutura}

$\mathrm{Na}$ superestrutura, mesmo com a pavimentação asfáltica em razoável estado de conservação, foi observada a ausência da junta de dilatação nas extremidades do tabuleiro, de um sistema de drenagem, de pingadeiras e de passeios para pedestres, conforme pode ser visto na Figura 4 .

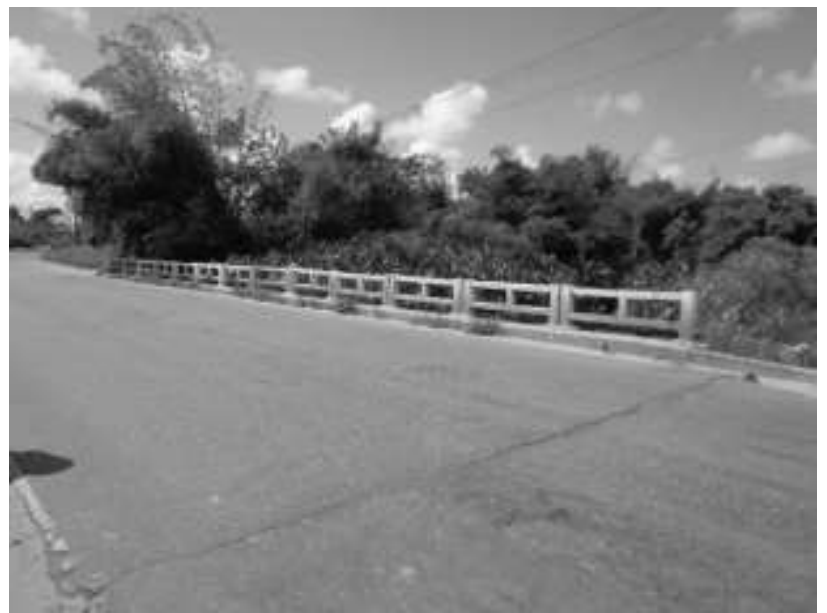

Figura 4: Ausência de junta e de passeios

O guarda-corpo e a barreira de proteção encontram-se em razoável estado de conservação. A ausência de pingadeiras nas extremidades laterais da laje favoreceu a infiltração de água, o aparecimento de manchas e a aceleração 
do processo de corrosão das armaduras das vigas e lajes conforme pode ser observado na Figura 5.

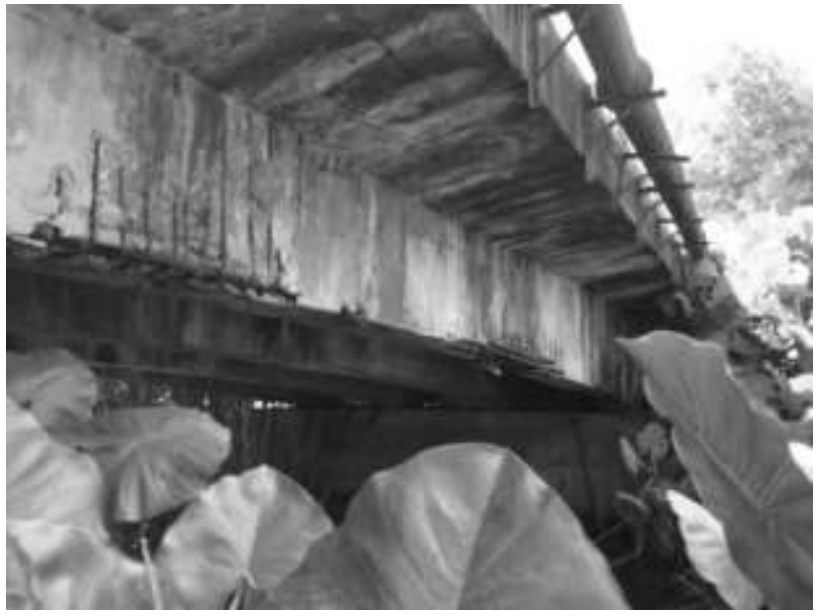

Figura 5: Ausência de pingadeira, contribuindo para o aparecimento de manchas no concreto e de corrosão nas armaduras

Das quatros longarinas, as duas intermediárias não apresentam maiores desgastes. Porém as extremas encontram-se em estado avançado de deterioração e apresentam sinais visíveis de grandes fissuras e destacamento do cobrimento, inclusive com grandes perdas da aderência entre as armaduras (de flexão e cisalhamento) e o concreto. As armaduras também estão com redução da seção transversal.

As longarinas internas bem como as transversinas, não apresentam este tipo de problema e sim de danos com menor gravidade, como fissuras e corrosões localizadas. Também foram constatadas eflorescências em todas as vigas transversais e longitudinais, e grande lixiviação nas vigas extremas.

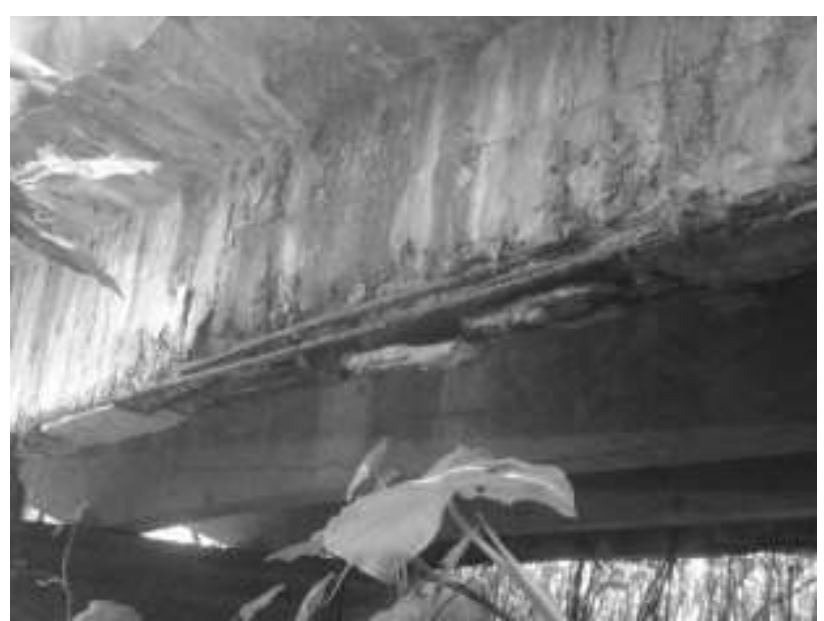

Figura 6: Vista de uma longarina extrema, mostrando a armaduras de flexão sem aderência e estribos destruídos.
A laje do tabuleiro apresenta desgaste generalizado causado principalmente pela infiltração de água pelo concreto poroso ao longo do tempo, associado à exposição de armaduras pelo pouco cobrimento que era exigido pelas normas da época em que a ponte foi construída. As figuras $6,7,8$ e 9 mostram aspectos do grau de deterioração estrutural das longarinas, em especial das extremas.

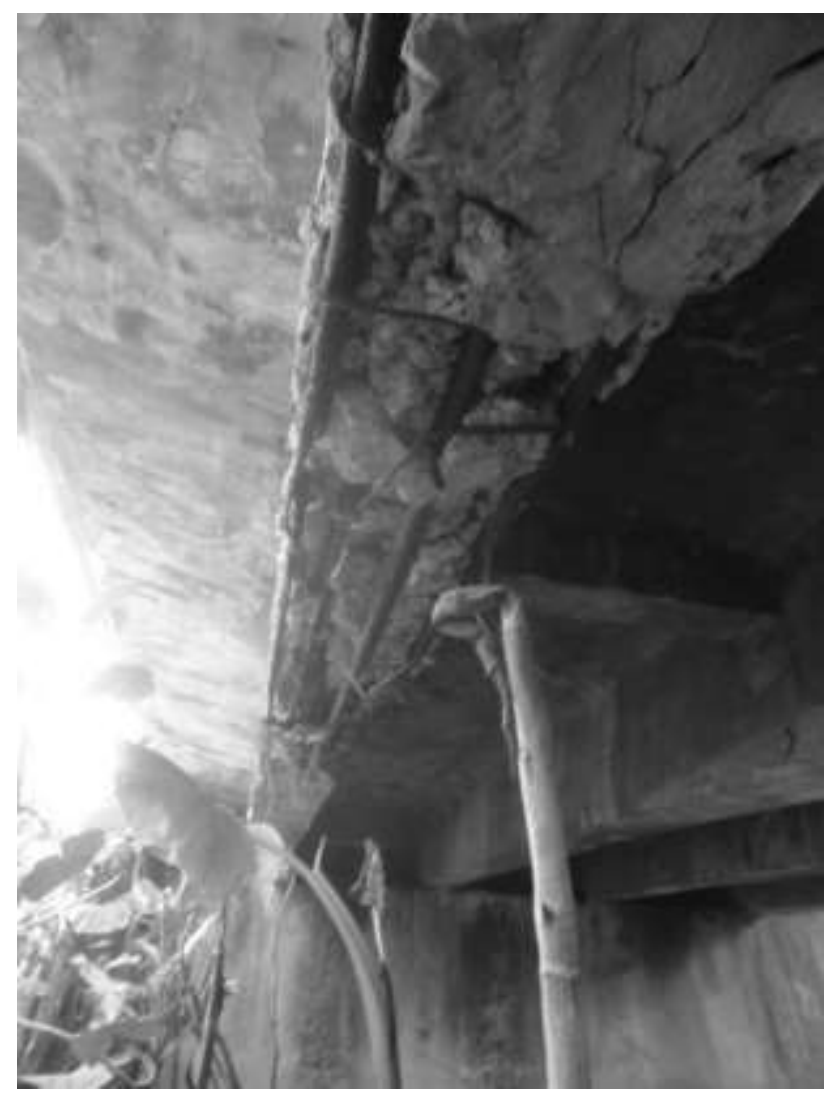

Figura 7: Perda total de aderência das armaduras e destruição do concreto.

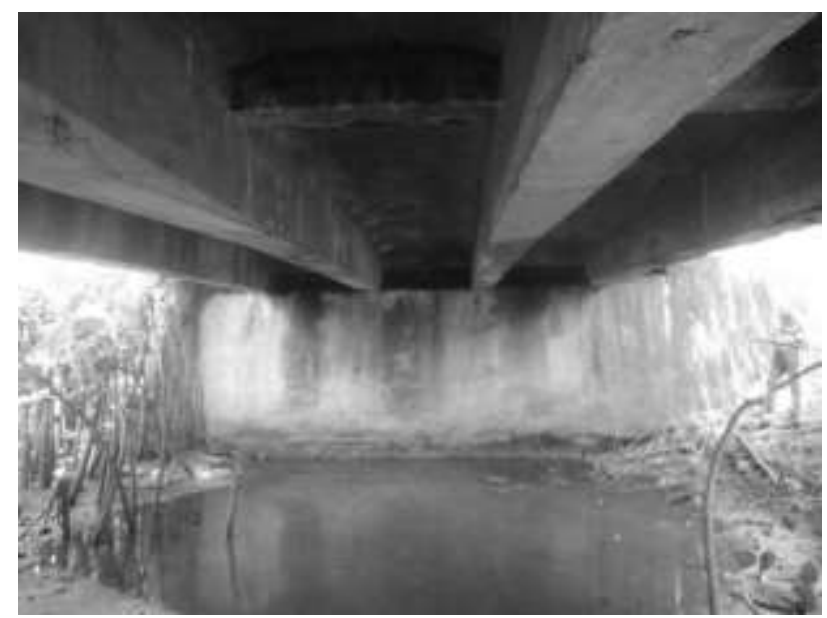

Figura 8: As duas longarinas internas sem sinais visíveis de manifestações patológicas graves. 


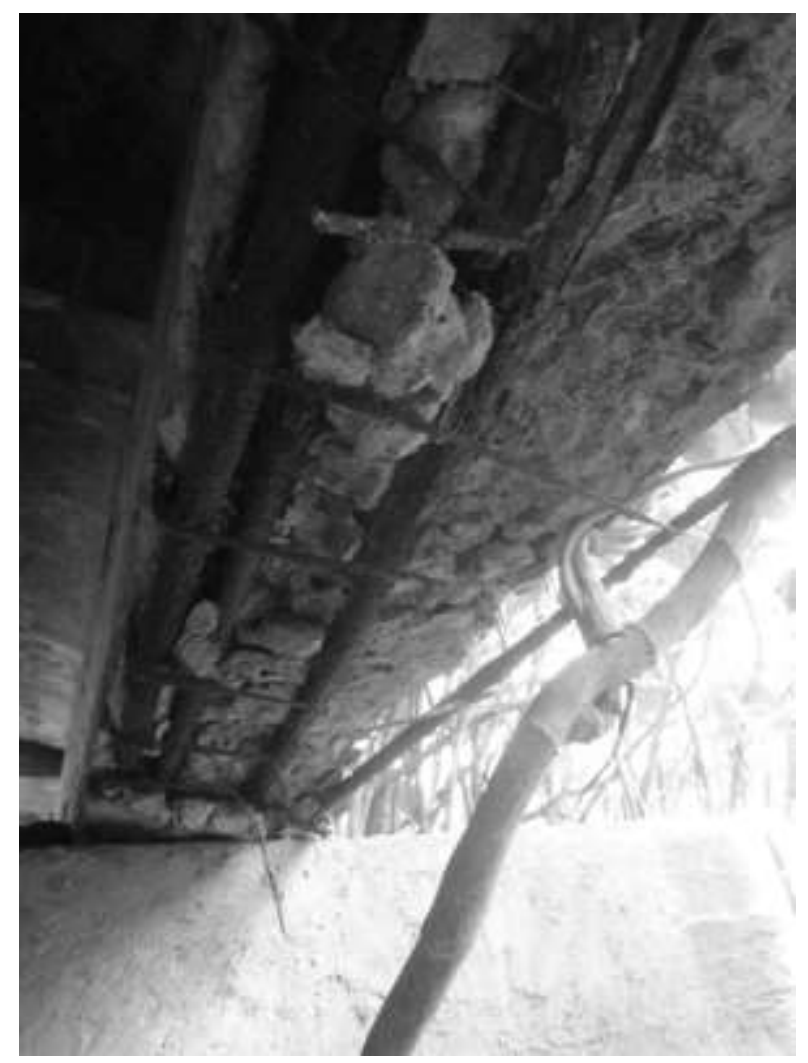

Figura 9: Situação da maior gravidade na face inferior de uma das longarinas extremas, com destruição total das armaduras e do concreto.

\subsubsection{Na mesoestrutura}

As vistorias meramente visuais não permitiram identificar grande problemas nos encontros nem no pilarparede do apoio central. Porém, verificou-se que os pêndulos que funcionam como aparelhos de apoio em uma das extremidades das longarinas estão seriamente avariados e embora não seja possível afirmar que ainda estejam cumprindo com as funções para as quais foram projetados, significam uma situação preocupante pela importância de tais componentes na transmissão dos esforços do tabuleiro para os encontros e fundações.

Um desses pêndulos (o que serve de apoio a uma longarina extrema) está seriamente danificado, com o concreto parcialmente destruído e as armaduras expostas, corroídas e sem aderência, como pode ser visto na Figura 10.

Os encontros e o pilar- parede do apoio central embora tenham muitas manchas proveniente das infiltrações do tabuleiro e algumas fissuras discretas, não apresentam sinais visíveis de desaprumos, deslocamentos ou deformações que possam significar algum problema estrutural, conforme mostram as figuras $11 \mathrm{e} 12$.

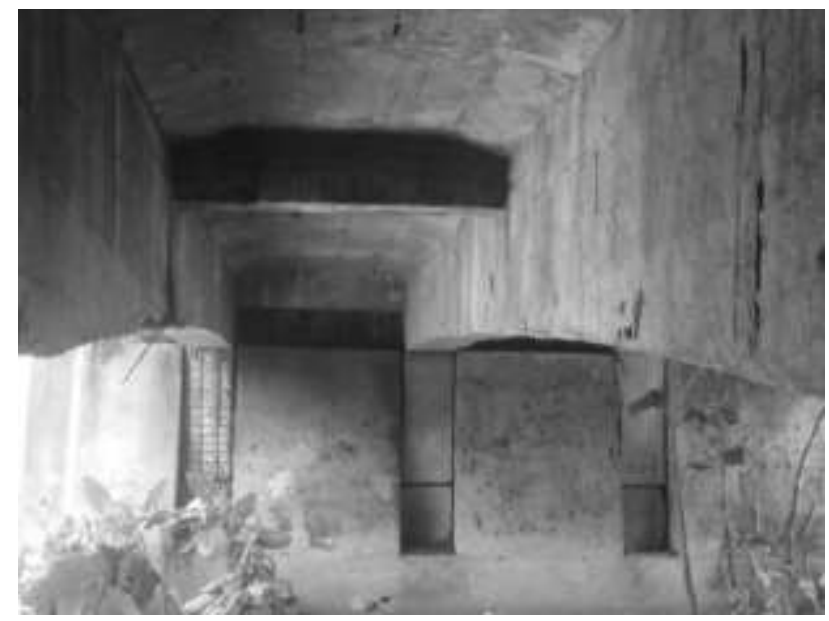

Figura 10: Pêndulo que apoia viga extrema com corrosão e destacamento do concreto.

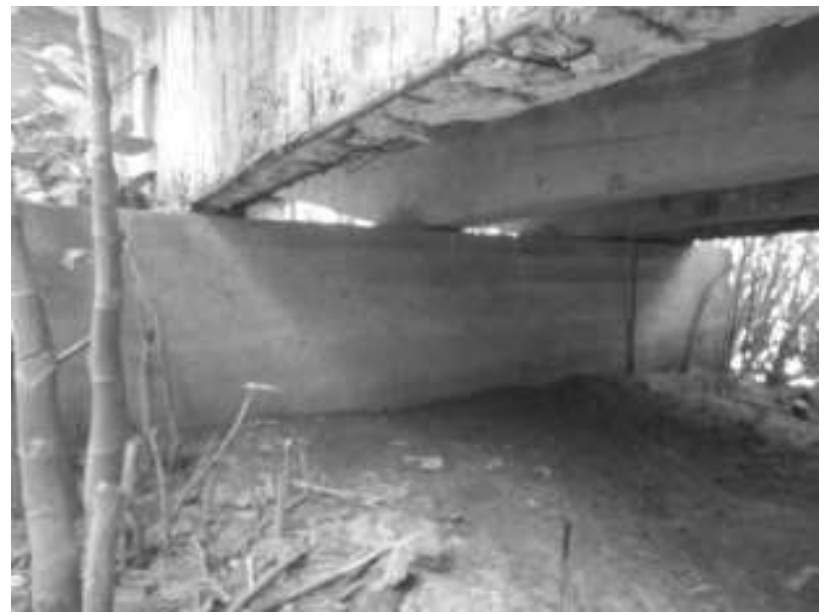

Figura 11: Pilar parede do apoio central não apresenta sinais de fissuras e deslocamentos e desaprumos

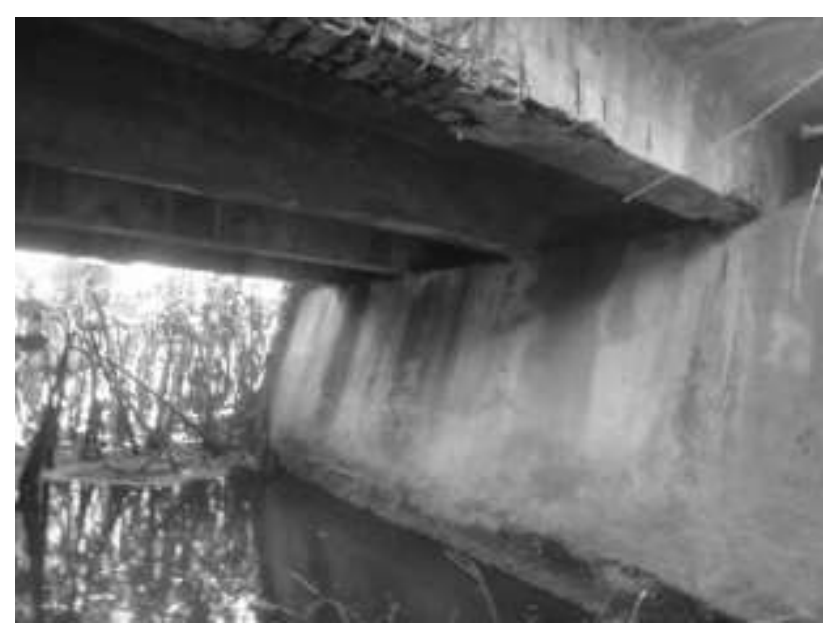

Figura 12: Os encontros apresentam manchas, mas não tem sinais de fissuras e deslocamentos. 
Nas figuras 13 e 14 está indicado o apoio de uma das longarinas sobre- o pilar-parede central, mostrando a dificuldade de identificar a existência ou o tipo de aparelho de apoio, levando a crer tratar-se de chapas de chumbo, pela pouca espessura observada da camada entre o fundo da viga e o topo do pilar.

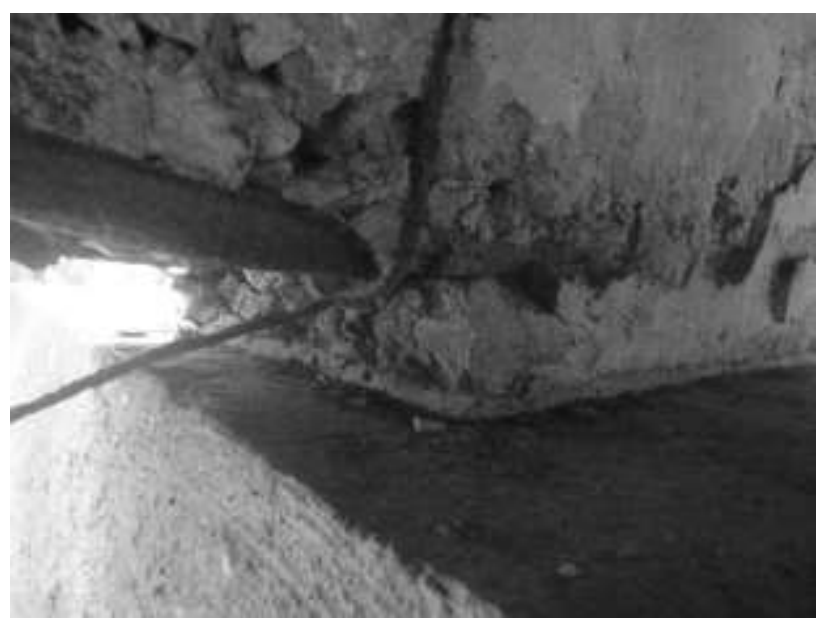

Figura 13: Detalhe do apoio central das longarinas, presumindo ser do tipo chapa de chumbo ou a inexistência de aparelho de apoio.

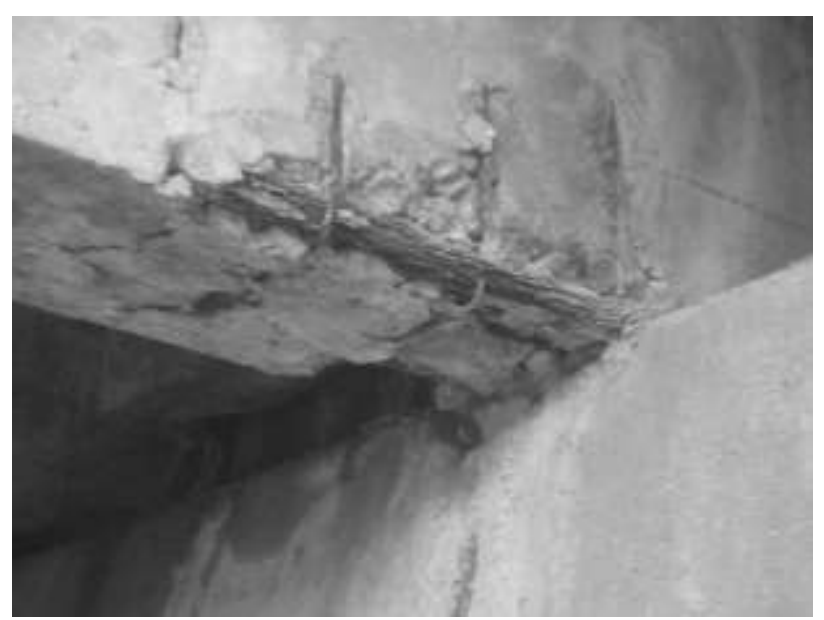

Figura 14: Detalhe do apoio da longarina sobre o encontro do lado oposto aos pêndulos, indicando tratar-se de chapas de chumbo ou a ausência de aparelhos de apoio pela destruição por esmagamento do concreto em zona de compressão.

\subsubsection{Na infraestrutura}

Durante as inspeções e análises realizadas não foi possível identificar o tipo de fundação adotado no projeto original da ponte. Tendo em vistas as características geotécnicas locais indicarem solo de má qualidade, presumese que se tratam de fundações profundas, em estacas ou tubulões. Porém, independentemente do tipo de fundação existente, não há como caracterizar problemas na infraestrutura, com base nas observações meramente visuais. Também, pelo mesmo motivo, não há como afirmar a integridade estrutural das fundações.

\section{Conclusões e Recomendações}

\subsection{Conclusões}

O surgimento de problemas patológicos é muito comum em pontes. As patologias causam uma redução nas propriedades de resistência dos materiais e do desempenho da estrutura como um todo, afetando consequentemente a durabilidade, e colocando em risco a integridade física das pessoas que diariamente utilizam a ponte para se locomoverem na rodovia.

A degradação estrutural da ponte em estudo, está associada a vários fatores tais como: a agressividade do meio ambiente, cobrimento insuficiente de armaduras, ausência de juntas de dilatação e de drenagem. Também foi observada a fixação inadequada de tubulações por meio de chumbadores, acarretando danos a estrutura conforme pode ser visto na Figura 15. Porém, a falta de manutenções preventivas e corretivas, sem dúvida, se constitui no fator mais preponderante para que a estrutura chegasse ao atual estado de deterioração, pois caso houvessem sido tomadas as devidas providencias na época adequada, a maioria das manifestações patológicas presentes não estariam em processo tão evoluído.

A seguir é feito um diagnóstico sobre os principais danos estruturais e manifestações patológicas que foram observados durante as vistorias e descritos no capítulo anterior:

Como foi detalhado anteriormente, os principais problemas estruturais da ponte referem-se ao estado de préruína das duas longarinas extremas do tabuleiro que certamente foi bastante influenciado pela ausência de pingadeiras nos bordos da laje, e também pelo fato de receberem diretamente as correntes de ar da atmosfera agressiva do local. Provavelmente a principal razão para o tabuleiro não ter entrado em colapso tenha sido a sua grande robustez, que era uma das características das antigas pontes rodoviárias.

A corrosão das armaduras e estribos está presente em vários pontos das vigas e lajes, tendo sido observado em muitos casos perda quase total das seções. A evolução desse processo se deu pelas causas já explicadas nos conceitos da revisão bibliográfica e também pelas peculiaridades da obra que também foram esclarecidas, com destaque para a falta de manutenção.

Aparentemente, essa Obra de Arte Especial da década de 1960 nunca passou por uma manutenção. Com o aumento do tráfego e da própria importância da BR -101 para a região, a ponte já deveria ter sido alargada e reforçada há muito tempo, principalmente ao se considerar a grande evolução das normas dos processos construtivos e do aumento nas resistências dos materiais estruturais, como é o caso do concreto. 
O meio ambiente agressivo e o baixo cobrimento, fatores de grande importância para o aparecimento de corrosões, são grandes exemplos de elementos que não eram considerados para a durabilidade nos projetos antigos

Hoje, de acordo com a norma vigente 6118/2014 vários aspectos foram levados em consideração para termos estruturas mais duráveis, como é o caso da classe de agressividade ambiental e a relação água cimento. Para a obra descrita, a mesma se enquadra na classe de agressividade forte III, o cobrimento a ser utilizado deverá ser no mínimo de $4,0 \mathrm{~cm}$ para vigas e pilares e de $3,5 \mathrm{~cm}$ para lajes, com uma relação água/cimento $\leq 0,55$.

A ausência de drenos e a falta de declividade para o escoamento das águas do tabuleiro, acabou causando infiltração na estrutura, acarretando deterioração das vigas e lajes através do processo de lixiviação, que dissolve e transporta os cristais de hidróxido de cálcio e magnésio diminuindo a resistência mecânica que na época chegava no máximo a um fck da ordem de $18 \mathrm{Mpa}$. Observamos também fissuras em vários pontos das lajes, vigas e ala, que mesmo não sendo ativas, contribuíram para o processo de corrosão. Muitas manchas e lixiviação também foram observados nos balanços laterais das lajes, devido à ausência de pingadeiras no bordo inferior, o que causou uma constante umidade ao longo dos anos.

Outro aspecto que não deve deixar de ser considerado ponte em estudo além do fato de provavelmente durante toda sua existência não ter passado por nenhum tipo de manutenção é que pelas características das manifestações patológicas existentes nas longarinas externas, é bastante provável que tenham sido originados na fase de execução. O concreto mal adensado pode ter sido o responsável pela segregação entre os agregados e a argamassa, ocasionando assim a perda precoce de aderência. Observamos também que os aparelhos de apoios do tipo pêndulo e em chapas de chumbo não mais funcionam, por causa da grande deterioração ocorrida ao longo do tempo

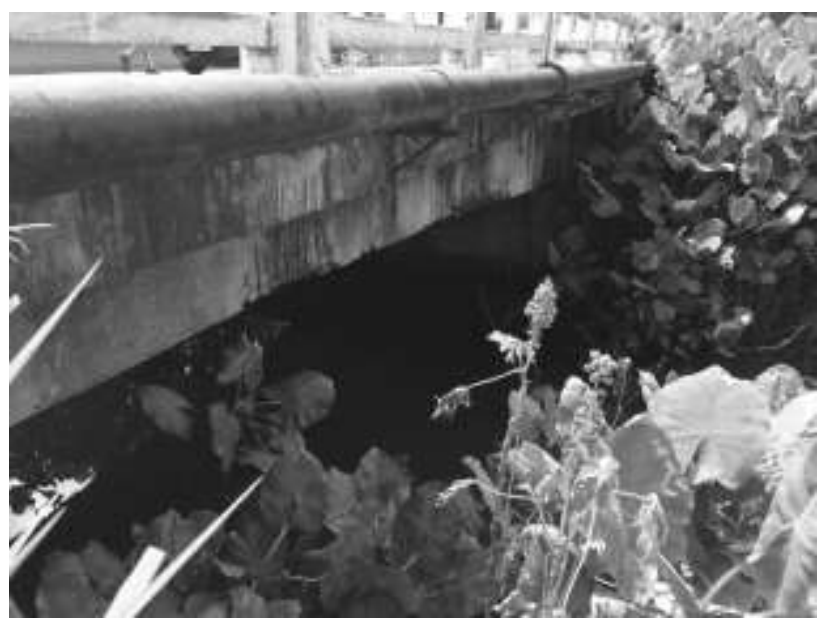

Figura 15: Fixação de tubulação por meio de chumbadores

\subsection{Recomendações}

A princípio, diante do exposto, é recomendável como uma primeira providencia emergencial, a execução de um escoramento provisório nas duas vigas da extremidade, com o objetivo de garantir a estabilidade da ponte, caso ocorra uma situação de ruptura em tais peças. Como solução definitiva, devido a sua importância e ao intenso tráfego da BR101 Norte, recomendamos o alargamento, reforço e recuperação da ponte, com a inclusão de dois passeios de pedestres e a implantação de uma adequada drenagem no tabuleiro por meio de dispositivos construídos por tubos de PVC, devendo ainda ser observada uma correta inclinação de $2 \%$ na pavimentação para um perfeito funcionamento do sistema.

Após o escoramento provisório, deverão ser executados os serviços de reforço e alargamento do tabuleiro, que poderá ser feito por um dos métodos atualmente adotados para as pontes convencionais de concreto da malha rodoviária brasileira. Estudos sobre em pontes rodoviárias brasileiras apresentados em trabalhos técnicos [10] e a própria experiência de especialistas, mostram que para tabuleiros com estas características, uma boa alternativa para alargamento é o método que utiliza concreto armado convencional moldado no local e concreto projetado. Esse método construtivo baseia-se no modelo de grelha, incluindo novas longarinas e solidarizando todas as vigas e lajes (novas e antigas) ao tabuleiro alargado.

É importante ressaltar que no caso da ponte sobre o rio Igarassu as vigas extremas necessitam ser totalmente reforçadas e recuperadas devido aos danos e patologias existentes, inclusive com o comprometimento da seção pela falta de aderência das armaduras de flexão e dos estribos. As vigas intermediárias certamente também precisam ser reforçadas. A Figura 16 mostra um exemplo de alargamento e reforço do tabuleiro de uma ponte antiga, com a adição de armaduras de reforço nas longarinas.

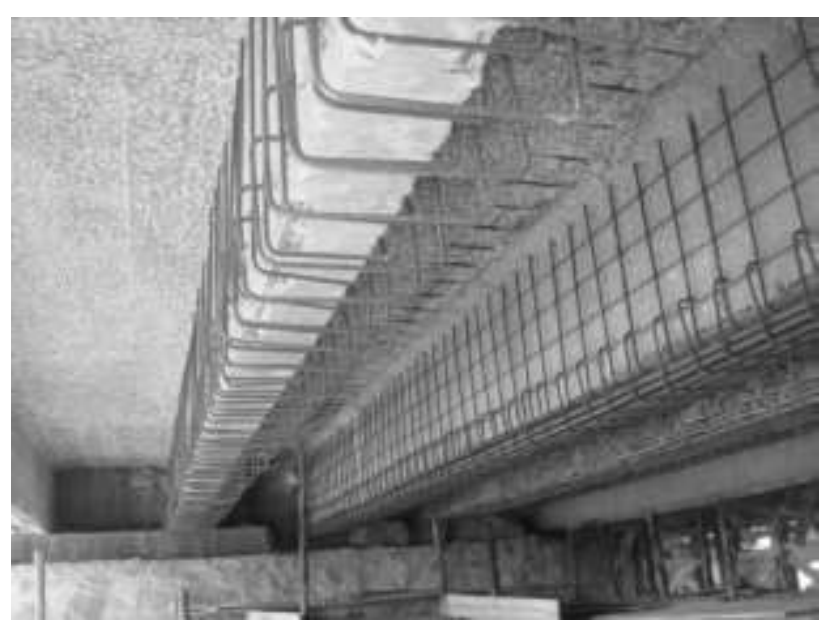

Figura 16: Exemplo de alargamento e reforço de uma ponte antiga com o uso de concreto armado convencional. 
Outras soluções de alargamento também poderão ser utilizadas, como é o caso dos sistemas estruturais com perfis metálicos ou vigas de concreto pré-moldado. Um exemplo da utilização de concreto projetado para esse tipo de reforço está ilustrado no exemplo da Figura 17.

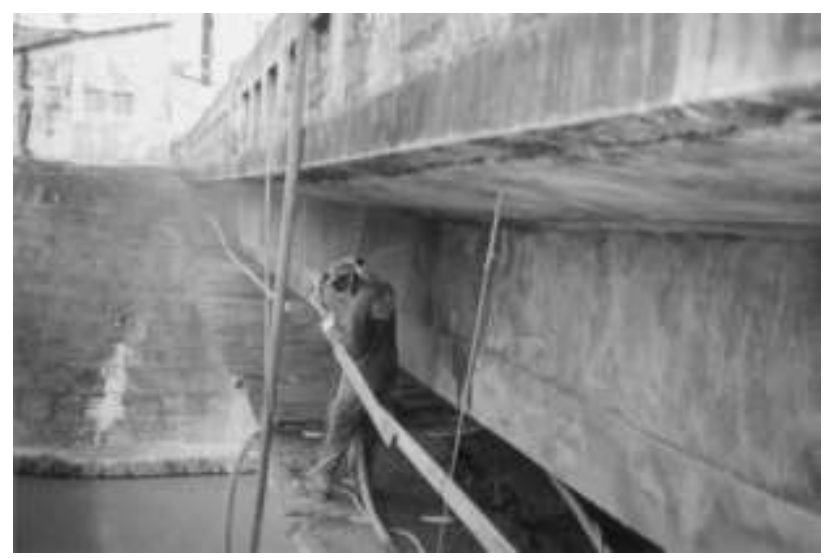

Figura 17: Exemplo da aplicação de concreto projetado no reforço das longarinas de uma ponte.

Outra questão importante a considerar é que o alargamento e reforço precisa contemplar a atualização das cargas móveis para o trem-tipo classe $450 \mathrm{KN}$, previsto pela norma NBR 7188/2013. Considerando a possibilidade da inexistência de aparelhos de apoio ou a existência de chapas de chumbo altamente deterioradas, sugerimos a colocação de aparelhos de neoprene por meio da operação de macaqueamento do tabuleiro. No caso dos pêndulos, como não exercem mais sua função, a sugestão é reforçar o encontro e substituí-los também por aparelho de apoio tipo neoprene.

Deverão também ser colocadas juntas de dilatação nas extremidades da ponte entre a laje e os encontros. Quanto aos encontros e pilar-parede, mesmo considerando que, aparentemente não apresentam sintomas visíveis que possam comprometer a segurança da ponte, deverão passar uma análise minuciosa antes da elaboração do projeto de alargamento, inclusive com a realização de prospecções geotécnicas e estruturais visando avaliar a integridade das fundações, tendo em vista que haverá um acréscimo de cargas na estrutura e consequentemente também nos esforços transferidos para as fundações.

Por fim, após a realização das obras de alargamento e reforço, faz-se necessário a elaboração de um plano de manutenção preventiva para garantir um acréscimo na vida útil da estrutura recuperada.

Evidentemente, uma gestão de pontes eficaz deverá sempre se basear em um rigoroso cadastro de todas as obras que compõe determinada rodovia e em um programa de vistorias sistemáticas. Deverá, ainda, incluir diversas atividades técnicas, organizacionais e administrativas com o objetivo de instruir e pôr em prática uma política que contemple a conservação, a recuperação, a ampliação e a substituição de obras [9].

A manutenção da ponte sobre o rio Igarassu, que foi objeto deste artigo, deverá estar inserida em um plano de conservação mais abrangente que envolva todas as pontes do trecho da BR 101 onde está localizada. Algumas questões não devem deixar de ser consideradas para que um sistema de manutenção e gestão de pontes alcance os seus objetivos: A primeira delas é a qualificação do pessoal técnico e administrativo que irá realizar as vistorias, fazer os relatórios, atualizar as informações cadastrais obtidas no campo e operar o sistema de gestão de pontes na sua totalidade.

Outra questão fundamental para a viabilização de todo o processo de conservação, recuperação, reforço e avaliação sistemática da avaliação das obras de Arte Especiais é a previsão de tais despesas no orçamento do Órgão responsável. O Figura 18 mostra de forma resumida as principais etapas que deverão fazer parte de um plano de manutenção e gestão de Obras de Artes Especiais.

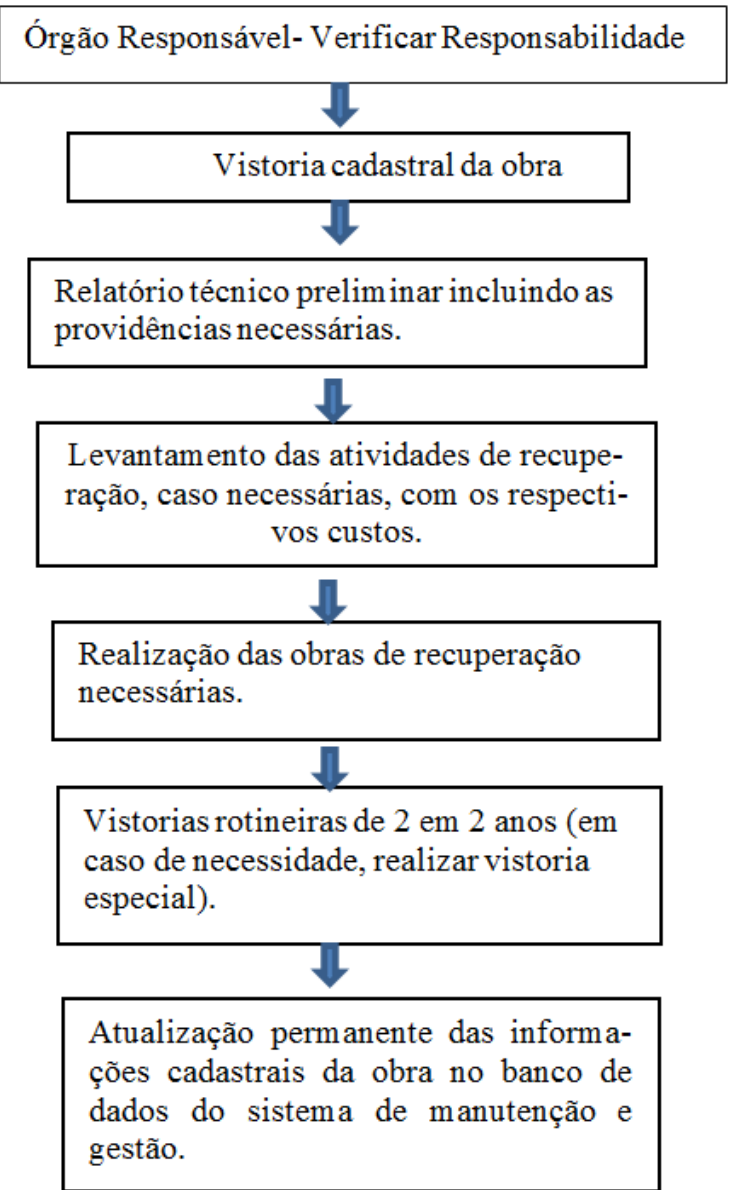

Figura 18: Fluxograma de um plano de manutenção e gestão de Obras de Artes Especiais. 


\section{Referências}

[1] D.P.Oliveira. Levantamento de Causas de Patologias na Construção Civil. http://monografias.poli.ufrj.br/monografias/mon opoli10007893.pdf, Agosto 2013.

[2] E.M.Barreto.Nota de Aula da Disciplina Manifestações Patológicas em Estruturas de Concreto. Curso de Especialização em Inspeção e Recuperação de Estruturas. 2015.

[3] P.R.L. Helene.Corrosão em Armaduras para Concreto Armado. Pini. São Paulo. 1986.

[4] V.Gentil.Corrosão.LTC -Livros Tecnicos e Científicos Editora.Rio de Janeiro.1994

[5] J. Nakamura. Concreto, Cuidados para Resistir à Maresia. Téchne. Edição88: Julho 2004.

[6] A.Werle. Carbonatação do concretoFenolftaleína-

na.aldowerle.blogspot.com.br/2012/09/carbonata cao-do-concreto-fenolftaleina.html. 05.04.2016

[7] www.ecivilnet.com/dicionario/o-que-elixiviacao.html.05.04.2016

[8] E.A.B.Gonçalves.Estudo de Patologias e suas causas nas Estruturas de Concreto Armado de Obras de Edificações.http//monografias.poli.ufrj.br/monografias/ monopoli10014879.pdf 06.04.2016.

[9] J.A.P. Vitório.Pontes Rodoviárias, Fundamentos, Conservação e Gestão.CREA-PE. Recife. 2002.

[10] J.A.P. Vitório.Um Estudo Comparativo sobre Métodos de Alargamento de Pontes Rodoviárias de Concreto Armado com a Utilização das Normas Brasileiras e Eurocódigos, Tese de Doutorado, Faculdade de Engenharia Universidade do Porto, mês, 2013 